\title{
The Risk Calculation of Hazardous Zones Created by Flammable and Explosive Chemicals, LPG Tank Example
}

\author{
Bulent Buyukkidan $^{1}$ iD, Huseyin Gumus ${ }^{2 *}$ iD, Ömer Ahmet Uslu1 ${ }^{1}$ \\ ${ }^{1}$ Department of Chemistry, Kutahya Dumlupinar University, Kutahya/Turkey \\ ${ }^{2}$ Osmaneli Vocational School, Bilecik Seyh Edebali University, Osmaneli, Bilecik/Turkey
}

Received: / Accepted: 16-November-2021 / 16-December-2021

\begin{abstract}
The determining of hazardous areas created by flammable and explosive chemicals is important to obtain a safe working environment. Taking precautions and prevent explosions require detailed investigations and accurate calculations instead of superficial and personal experience. In this context, possible leakages and leaks occurring around the LPG tank and its connections in a real enterprise were evaluated and the border of possible explosive atmosphere areas was calculated by the ALOAH program according to the TS 60079-10-1 standard. Based on the secondary discharge of the LPG from the bottom of the tank, the discharge characteristics were calculated as 4.946578 and $3.926692 \mathrm{~m}^{3} / \mathrm{s}$ at sonic and subsonic conditions respectively, and region radii, $10.8 \mathrm{~m}$. The explosive atmosphere of the LPG tank was concluded that matched well the definition of Zone 2. The risk severity score of explosive atmospheres was calculated as 12 by using the risk assessment method of matrix system with approximations, possible in a week (3P), and the effect that could cause serious injury (4P). Serious threats and devastating effects were fictionalized clearly by explosion scenarios of the LPG tank. The calculations of explosive borders for flammable chemicals are necessary to prevent explosions, fires, and toxic effects of leaked chemicals by taking measurements on time. It is also necessary to calculate explosive areas and possible sceneries for each chemical separately for accurate results and effective control.
\end{abstract}

Key words: Flammable and explosive chemicals, ATEX, hazardous environment, LPG

\section{Introduction}

Explosion or burning risk occurs because of leakage of liquids or gaseous chemicals that can easily evaporate in room conditions or at higher temperatures. This usually occurs when flammable explosive materials leak or pour into the environment during transfer from containers or valves where they are contained, and then merge with the ignition source. If there is enough oxygen in the environment, the third component required for fire is a spark (fire inductor) for combustion or explosion. For a substance to burn or explode, the substance and oxygen must be mixed in a certain proportion. The percentage ratio of air and flammable substance to the total mixture is determined as the explosion limit of that substance [1,2]. Thus, the flammable material that spreads to the environment and mixes with air at appropriate rate creates an explosive atmosphere. This ratio is called the flammability limit. The flammability limit of the $\mathrm{CO} / \mathrm{H}_{2} / \mathrm{N}_{2} /$ air mixture compared in the presence of limited oxygen [3], the highest flammability limits of hydrocarbons diluted with inert gas [4], and the explosion behaviour of the hydrogen-enriched natural gas mixture have been investigated [5]. It is understood that the air mixture required for the explosion of each explosive chemical is different.

\footnotetext{
*Corresponding author e-mail: huseyin.gumus@ bilecik.edu.tr
} 
The Risk Calculation of Hazardous Zones Created By Flammable And Explosive Chemicals, LPG Tank Exampl...

The pressure formed as a result of the amount of the reactant and products may cause damage to the structures around the explosion source, collapse of the walls and cause serious material damage and even accidents that may result in death. As a result of the explosion in the Istanbul Davutpaşa industrial site in 2008, 21 people died and 117 were seriously injured, 2 people died and 2 people were injured as a result of the explosion of the epoxy resin reactor in Tuzla, Istanbul in 2011, On October 11, 2017, a large-scale explosion occurred in the Tüpraş Izmir refinery with the combination of naphtha vapor with spark, and major damage occurred [6].

An explosion occurs when gas, liquid or solid materials that mixed with oxygen in the appropriate ratio exposed to the igniter. Some of the most used gases with high explosion risk in the industry are methane, propane butane, hydrogen, acetylene, and LPG. Each of these gases has its own specific explosion mix rates with air. In addition, the flash point, which is defined as the point where the vapours of flammable substances and suitable mixtures of oxygen meet the igniter, and the ignition temperatures at which it ignites when heated without any igniter are also important factors that determine the explosion conditions. The flash and ignition temperatures of ethyl alcohol were recorded as $13.7^{\circ} \mathrm{C}$ and $362.7^{\circ} \mathrm{C}$ respectively [7]. Another important industrial chemical that has the potential to create explosive atmosphere because of its spread to the environment is LPG, known as liquefied petroleum gas. Dust of solid substances can also create explosive atmosphere when they form a suitable mixture with air. This situation is technically defined as explosion of powders which have ignition energy less than $25 \mathrm{~mJ}$. Low humidity and high ambient temperature further reduce this energy and increase the risk of explosion. Special precautions, clothes and measures to increase ambient humidity are applied for dusts with ignition energy less than $10 \mathrm{~mJ}$. An explosion occurs when electrical arcs, mechanical friction, hot surfaces and static electricity sources, which are considered as involuntary ignition sources, come into contact with oxygen mixed with flammable gas, liquid or solid at an appropriate rate.

In order to be protected from such explosive environments with effective and technical measures, the European Union directive on atmospheric explosions ATEX 95 has been put into practice. ATEX was translated into Turkish by the same name and that was included in the occupational health and safety legislation applicable in Turkey. The standard 99/92 / EC, defined as ATEX 137 or ATEX Workplace Directive, contains the minimum requirements for the protection of workers from the risks of explosive atmospheres. This directive is also basic basis for the dated 30.04.2013 and numbered 28633; "Regulation on the Protection of Employees from the Dangers of Explosive Environments". There is no precise definition of what atmospheric conditions are mentioned in this directive and related regulations. But in general terms: conditions where pressure values in the range of 0.8-1.1 bar and a mixture temperature between $-20{ }^{\circ} \mathrm{C}$ and $+60{ }^{\circ} \mathrm{C}$ are provided as atmospheric conditions and these German EX-RL definitions are used as the values [8]. To be protected from the damages of explosive atmospheres, these environments should be well known. Based on the ATEX directive, atmospheres suitable for explosion are divided into zone classes in accordance with the TS 60079-10-1 standard, depending on the duration and frequency of the atmosphere with the risk of explosion. These regions are Zones 0, 1, 2 for gases and vapours as Zone 20, 21, 22 for dusts are named from the most effective and dangerous to less dangerous. The description of effectiveness for all types of explosives is from very impact to low, often explosive, occasionally, and rarely. Explosion risk should be defined to avoid explosive atmosphere and necessary precautions should be taken to protect employees from dangers arising from explosive environments. The first of these measures is to eliminate at the source, the second effective method is to prevent the spread of solid, liquid or gaseous substances that will create 
an explosive atmosphere. Leaks arising from inlet and outlet valves, connections, pumps, and other equipment, where easily evaporative liquids and gaseous substances in room conditions mix into the ambient air from the containers where they are stored, should be controlled, and eliminated. Creating an adequate and effective ventilation system to dilute the amount of substance in the environment is the most important control method after removal at source. Thus, the flammable explosive substance can be prevented from reaching the explosion limit. Scenarios and countermeasures for any explosion situation should be developed with the calculations to be made considering the shape of the leakage places, leakage time, type of leakage and chemical properties and the employees should be protected from explosive atmosphere hazards. In this study, the possible explosive atmosphere limits around the LPG tank used in a real enterprise were determined using the ALOHA program. Taking these calculations into consideration, risk assessment and recommendations are specified to protect employees from possible explosion risks. It is important to use advanced technological programs and materials within integrated disaster prevention program to determine occupational threats more successfully for not only industrial but also natural disasters such as flow and earthquake $[9,10]$.

\section{Material and Method}

In this study, the determination of the points released from the LPG tank in an enterprise operating in the chemical field and having the potential to create explosive atmosphere was calculated using the ALOHA program according to the TS 60079-10-1 standard. The hazardous area is defined by determining the impact area of LPG released from the tank bottom and from the pump flanges. Necessary measures and suggestions have been determined according to the risk assessment made using these calculation values.

For this, the following equations specified in the TS 60079-10-1 standard prepared by IEC (International Electrotechnical Commission) and translated into Turkish by TSE will be used. The zone qualifications and distances of the leaking chemical specified in the regulation, the spread areas, and characteristics of the explosion as a result of the possible explosion will be calculated using the ALOHA modelling program. Considering the numerical data to be obtained, the probability of dangerous situations that may occur as a result of leakage and the damages that may be caused by these dangerous situations will be made according to the Ltype risk assessment matrix, precautions and equipment will be specified. The discharge rate (W) of the chemical that creates the risk of explosion from the container is calculated according to the equation given in Table 1 .

Table1. Chemical discharge rate $\left(\mathrm{W}_{\mathrm{g}}\right)$ equation, $\mathrm{kg} / \mathrm{s}$

\begin{tabular}{cccl} 
Equation & Parameter & Unit & Explanation \\
\hline $\boldsymbol{W}_{\boldsymbol{g}}=\boldsymbol{C}_{\boldsymbol{d}} \boldsymbol{S} \sqrt{\mathbf{2} \boldsymbol{\rho \boldsymbol { P }}}$ & $\mathrm{W}_{\mathrm{g}}$ & $\mathrm{Kg} / \mathrm{s}$ & Discharge rate \\
$\mathrm{C}_{\mathrm{d}}$ & - & Discharge coefficient \\
$\mathrm{S}$ & $\mathrm{m}^{2}$ & Discharge area \\
$\rho$ & $\mathrm{Kg} / \mathrm{m}^{3}$ & Liquid density \\
$\Delta P$ & $\mathrm{~Pa}$ & $\begin{array}{l}\text { Pressure difference at } \\
\text { discharge area }\end{array}$
\end{tabular}

The chemical's discharge characteristic (DC) calculation was made using the equation in Table 2 by using the discharge rate to occur from the leakage cross section per second. 
The Risk Calculation of Hazardous Zones Created By Flammable And Explosive Chemicals, LPG Tank Exampl...

Table 2. Discharge characteristic (DC) of the chemical, $\mathrm{m}^{3} / \mathrm{h}$

\begin{tabular}{|c|c|c|c|}
\hline Equation & Parameter & Unit & Explanation \\
\hline & $\mathrm{DC}$ & $\mathrm{m}^{3} / \mathrm{s}$ & Discharge characteristic \\
\hline Discharge Characteristic & $\mathrm{W}_{\mathrm{g}}$ & $\mathrm{Kg} / \mathrm{s}$ & Discharge rate \\
\hline$=w_{g}$ & $\mathrm{k}$ & - & Safety coefficient \\
\hline$\overline{\rho_{g} * k * L F L}$ & $\rho$ & $\mathrm{Kg} / \mathrm{m}^{3}$ & Vapor density \\
\hline & LFL & Vol/vol & Lower flammability limit \\
\hline
\end{tabular}

$\mathrm{W}_{\mathrm{g}}$ and DC values are used to determine the degree of dilution (DDL). The area where the point where these two values intersect is on the graph of the ventilation velocity against the bleeding characteristic gives the degree of dilution. The probable size of the leak in the area where the leak occurred can be determined if the type of leak is known from the drain characteristic versus distance graph.

In order to determine the air flow velocity, the properties of the chemical substance and the open or closed, i.e. air inlet and outlet feature of the environment should be considered. Considering these and other necessary parameters, the calculator finds the most appropriate ventilation value from the ventilation and zone (ZONE) type table given according to EN 60079 -10-1 standard and uses it in the necessary calculations (Table 3). In this study, the ventilation velocity was evaluated as $0.5 \mathrm{~m} / \mathrm{s}$ by evaluating the ambient conditions.

Table 3. Ventilation speed chart

\section{Open space types}

\section{Barrier-free sections}

Blocked sections

High from ground level

Estimated air flow rates to reduce light gas or vapor releases from the molecular mass of the air $(\mathrm{m} / \mathrm{s})$

Estimated air flow rates to reduce heavy gas or vapor emissions from the molecular mass of the air $(\mathrm{m} / \mathrm{s})$

Required air flow velocity to vent the evaporating amount of liquid accumulated pool at random height level $(\mathrm{m} / \mathrm{s})$

\begin{tabular}{|c|c|c|c|c|c|}
\hline$\leq 2$ & $\geq 2$ & $>5 \mathrm{~m}$ & $\leq 2 \mathrm{~m}$ & $\geq 2$ & $>5 \mathrm{~m}$ \\
\hline & & & & & \\
\hline 0.5 & 1 & 2 & 0.5 & 0.5 & 1 \\
\hline 0.3 & 0.6 & 1 & 0.15 & 0.3 & 1 \\
\hline & $>0.25$ & & & $>0.1$ & \\
\hline
\end{tabular}

\footnotetext{
*For closed areas, $0.5 \mathrm{~m} / \mathrm{s}$ ventilation speed value is generally accepted. There must be special circumstances in order to accept different values (eg points where air inlet and outlet are provided). The mechanism used for ventilation should be controllable and the minimum air flow rate should be calculated.
}

\section{Results}

It has been determined by expert examinations that the LPG tank subject to the study has two types of flange connections, one is in the pump line and the other is under the tank. The parts 
of these flanges that leak or are suitable for LPG leakage were examined and dangerous areas were determined in case of possible leakage. The representation and calculated distribution distances of the chemical leakage caused by the tank in case of possible leakage are given in Figure 1 .
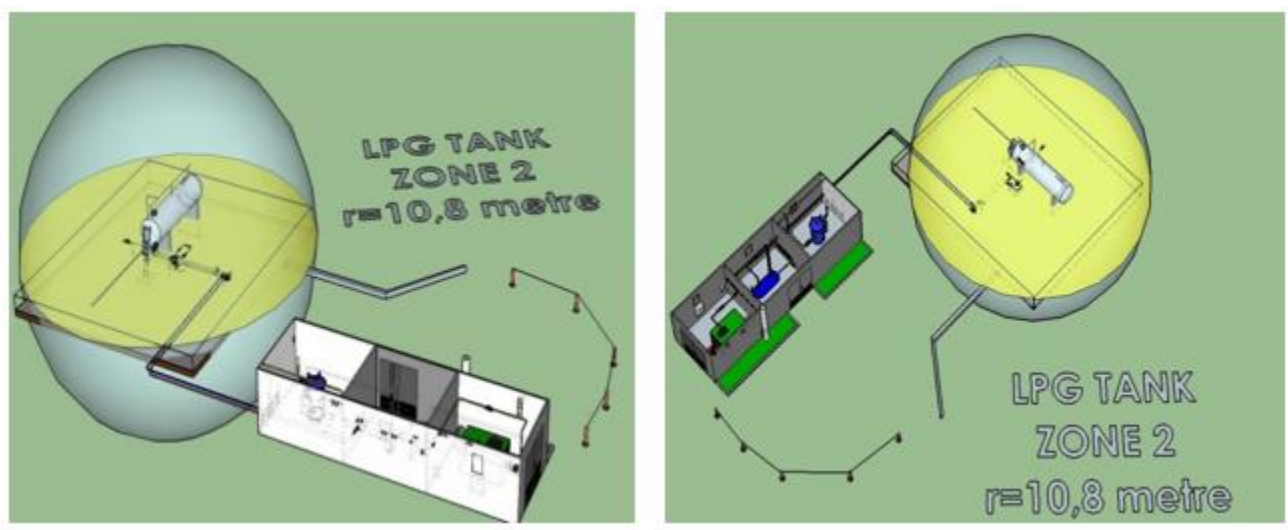

Figure 1. Representation of the zone which the LPG leakage is dispersed from different perspectives

\subsection{Classification of dangerous area}

The classification of the hazardous area has been decided considering the discharge characteristics in the ventilation efficiency table (Table 4). It has been concluded that both leakage environments comply with the definition of danger known as Zone 2, which is defined as "places where explosive atmosphere created by air mixtures of flammable substances in the form of gas, vapor and fog may occur occasionally under normal operating conditions". In Table 4, the points where the information on the dilution degree and the discharge pattern intersect give the class of the danger zone. The discharge source refers to the area where the flammable chemical leaks into the environment, causing an explosive atmosphere. The discharge type of the chemical is classified into three groups according to the leakage state and the leakage time. In this study, the area shown in yellow represents the area where the leak is $[9,11,12]$.

a)Continuous discharge source: Situations in which the discharge occurs continuously for a long time or for a short time and frequently,

b)Main discharge source: Situations where discharge occurs at regular intervals or occasionally under normal process conditions,

c) Secondary discharge source: Covers situations where discharge is not expected to occur under normal process conditions but can occur sparsely and for a short time.

In our study, it was decided that the leaks in the LPG tank were generally in the form of secondary discharge, considering that they occur during the loading or delivery of LPG to the system. Since the LPG shipment is made automatically from the main control desk, the valves under the tank normally remain closed. Material passes through both upper and lower flanges during shipment and there is a possibility of leakage. The type of leakage plays an important role in the most accurate calculation of the explosion probability. 
The Risk Calculation of Hazardous Zones Created By Flammable And Explosive Chemicals, LPG Tank Exampl...

Table 4. Ventilation efficiency table

\begin{tabular}{|c|c|c|c|c|c|c|c|}
\hline \multirow{4}{*}{$\begin{array}{l}\text { Discharge } \\
\text { Degree }\end{array}$} & \multicolumn{7}{|c|}{ Ventilation Efficiency } \\
\hline & \multicolumn{3}{|l|}{ High Dilution } & \multicolumn{3}{|c|}{ Medium Dilution } & $\begin{array}{l}\text { Low } \\
\text { Dilution } \\
\end{array}$ \\
\hline & \multicolumn{7}{|c|}{ Reliability Degree } \\
\hline & Well & Average & Low & Well & Average & Low & $\begin{array}{l}\text { Well, } \\
\text { Average } \\
\text { or Low }\end{array}$ \\
\hline $\begin{array}{l}\text { Continuous } \\
\text { discharge }\end{array}$ & $\begin{array}{l}\text { Safe } \\
(\text { Zone } 0 \mathrm{Ne})^{\mathrm{a}}\end{array}$ & $\begin{array}{l}\text { Zone } 2 \\
(\text { Zone } 0 \mathrm{Ne})^{\mathrm{a}}\end{array}$ & $\begin{array}{l}\text { Zone1 } \\
(\text { Zone } 0 \mathrm{Ne})^{\mathrm{a}}\end{array}$ & Zone 0 & \begin{tabular}{|l} 
Zone $0+$ \\
Zone 2 \\
\end{tabular} & $\begin{array}{l}\text { Zone 0+ } \\
\text { Zone } 1\end{array}$ & Zone 2 \\
\hline $\begin{array}{l}\text { Main } \\
\text { discharge }\end{array}$ & $\begin{array}{l}\text { Safe } \\
(\text { Zone } 1 \mathrm{Ne})^{\mathrm{a}}\end{array}$ & $\begin{array}{l}\text { Zone } 2 \\
(\text { Zone } 1 \mathrm{Ne})^{\mathrm{a}}\end{array}$ & $\begin{array}{l}\text { Zone } 2 \\
(\text { Zone } 1 \mathrm{Ne})^{\mathrm{a}}\end{array}$ & Zone 1 & \begin{tabular}{|l|} 
Zone $1+$ \\
Zone 2 \\
\end{tabular} & $\begin{array}{l}\text { Zone } 1+ \\
\text { Zone } 2\end{array}$ & $\begin{array}{l}\text { Zone } 0+ \\
\text { Zone } 1^{\mathrm{c}}\end{array}$ \\
\hline $\begin{array}{l}\text { Secondary } \\
\text { discharge }^{\mathrm{b}}\end{array}$ & $\begin{array}{l}\text { Safe } \\
(\text { Zone } 2 \mathrm{Ne})^{\mathrm{a}}\end{array}$ & $\begin{array}{l}\text { Safe } \\
(\text { Zone } 2 \mathrm{Ne})^{\mathrm{a}}\end{array}$ & Zone 2 & Zone 2 & & Zone 2 & $\begin{array}{l}\text { Zone } 0+ \\
\text { Zone } 1^{\mathrm{c}}\end{array}$ \\
\hline \multicolumn{8}{|c|}{$\begin{array}{l}\text { Note: "+" means at around the mentioned area. } \\
\text { a: Zone } 0 \mathrm{Ne} \text {, Zone } 1 \mathrm{Ne} \text { and Zone } 2 \text { Ne Refers to theoretical regions with negligible dispersion limit under } \\
\text { normal conditions } \\
\text { b: The Zone } 2 \text { area created by the secondary discharge may exceed the area attributable to major or continuous } \\
\text { discharge degrees. In this case, the larger distance should be used. } \\
\text { c: Zone } 0 \text { is used if, in practice, the ventilation is too weak, and the dispersion is such that there is a continuous } \\
\text { gas environment (almost no ventilation). }\end{array}$} \\
\hline
\end{tabular}

The degree of dilution can be defined as the effectiveness of the discharge from a source to become safe from explosion and/or fire by mixing with air. Reducing the amount of chemicals discharged with artificial or natural ventilation to below the explosive value is a measure of neutralizing the source of danger in the environment. With high dilution, the amount of chemical around the discharge source rapidly decreases and almost no persistence after the discharge stops. Medium dilution: While the discharge continues, the chemical amount is taken under control by creating a stable zone limit value and the explosive gas environment is not permanent at a high level after the discharge is completed. Low dilution: Concentration is large while discharge is in progress and/or expressed as persistence of flammable environment after discharge is complete [13-15]. In our study, the dilution degree of both pump and bottom flanges was found to be "medium dilution" Figure 2. This indicates that the amount of LPG leaking into the environment is higher or equal than the value swept by air, so there is a danger of explosion or burning in medium ratio. The degree of dilution is included in the standards as the area where the values intersect in the chemical's discharge characteristic graph against the air flow velocity in the environment where the discharge source is located (the air flow velocity of the LPG source discussed in this study was determined as $0.5 \mathrm{~m} / \mathrm{s}$ using Table 4) [6]. 
The Risk Calculation of Hazardous Zones Created By Flammable And Explosive Chemicals, LPG Tank Exampl...

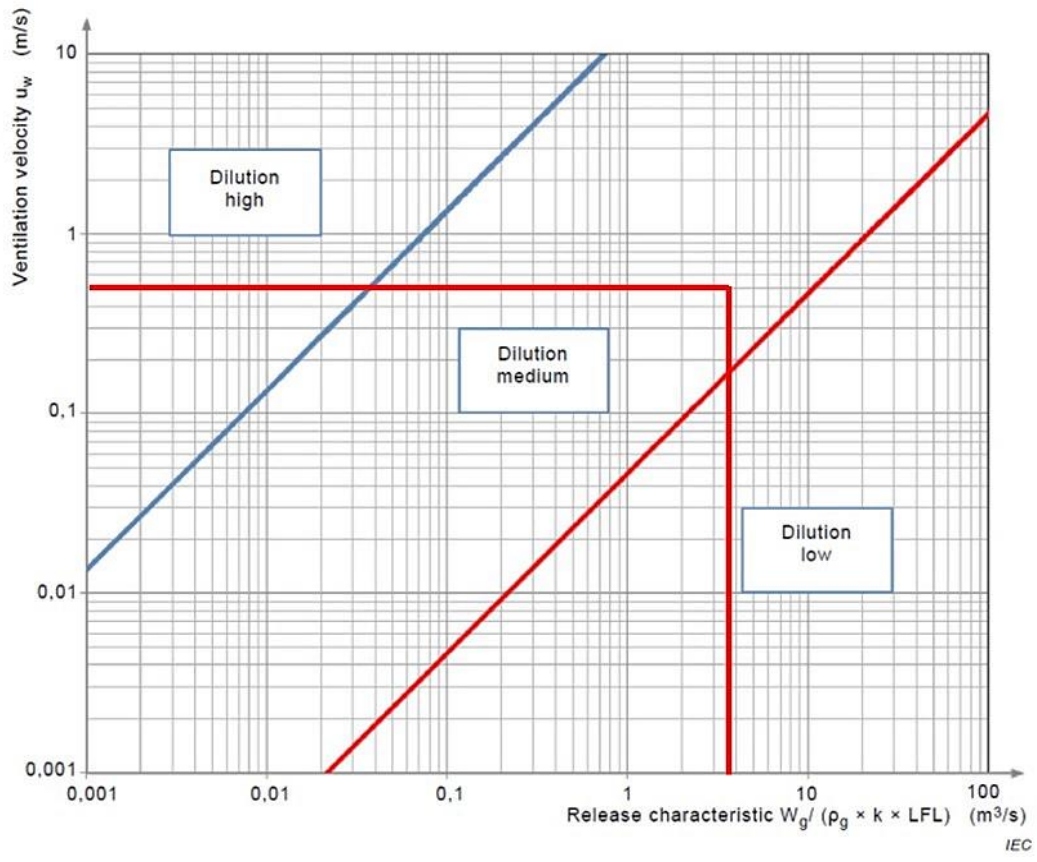

Figure 2. Air flow velocity-discharge characteristic graph used for dilution degree calculation

The discharge characteristic is one of the important data used to obtain basic values on the rate of spreading of gas or dust that can leak from a point to create an explosive atmosphere and danger zones [9]. The three definitions used in explaining the characteristics of the discharge are jet, diffusion, and heavy gas types. The discharge characteristics of the LPG tank was calculated as $3.926692 \mathrm{~m}^{3} / \mathrm{s}$ and 4,946578 at sonic and subsonic discharge conditions respectively. Jet Type Release: It is the discharge of a chemical from a leak with high pressure and high speed. In time, the jet emission dilutes and loses its effect without air flow. Diffusion Type Discharge: It is the release that disperses with low-speed diffusion or loses its separation momentum by hitting the surfaces it spreads. Heavy Gas Type Emission: These are heavy gas or vapor emissions that are distributed in the direction of horizontal surfaces [16].

In our study, it was evaluated that the emission from the LPG tank was heavy gas in both the upper and lower flanges, and it was used to calculate the emission distance. Heavy gas emission means the low exit of gas or dust, and its impact area is further than diffusion and jet type dispersion. As can be understood from its definition, the impact area heavy gas type emission is high, and the explosive ambient distance is high possibility due to lower dilution.

\subsection{Calculation of zone radii}

The calculation of the zone radii is made by determining the hazardous distances (m) corresponding to the discharge characteristic value on the line showing the emission type in the graph of the discharge characteristic versus the hazard distances. Accordingly, it is seen that the radius of the dangerous area formed by the line flanges is $10.8 \mathrm{~m}$ Figure 3 . Other features and evaluation results regarding the discharge points formed from the LPG tank are given in Table 5. Danger zones were characterized by numerical values in the calculations made using TS 60079 standard data and graphics. This study offers a scientifically based detection opportunity instead of determining the danger limits of explosive gas and dust substances with qualitative observations and experiences. Thus, more planned studies can be done to prevent dangerous situations from occurring. Success will increase in protecting employees from hazards. 
The Risk Calculation of Hazardous Zones Created By Flammable And Explosive Chemicals, LPG Tank Exampl...

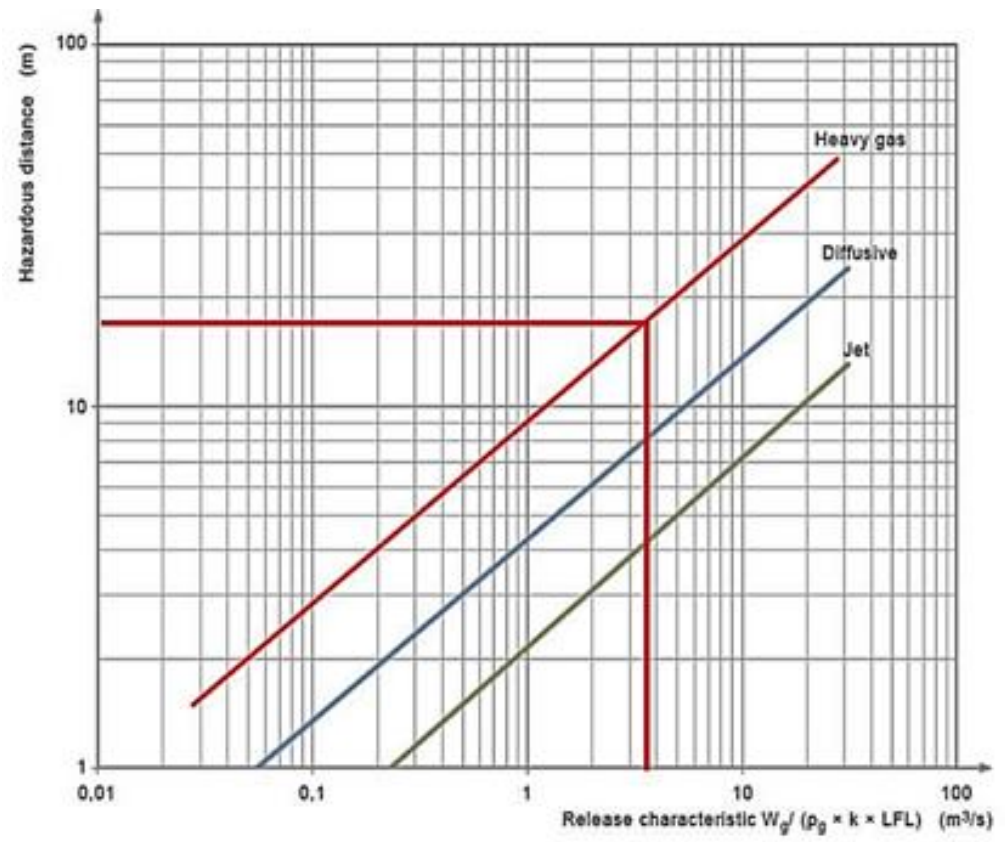

Figure 3. Emission type-discharge characteristic graph used for hazardous area distance calculation

Table 5. Features of LPG tank distribution

\begin{tabular}{|c|c|c|c|}
\hline Properties & Unit & Value & Sonic/Subsonic \\
\hline Molecular Weight-MW & $\mathrm{Kg} / \mathrm{kmol}$ & 53.9000000 & Sonic \\
\hline Leak surface area-S & $\mathrm{m}^{2}$ & 0.0001000 & $\begin{array}{l}\mathrm{W}_{\mathrm{g} \text { - discharge rate at sonic }} \\
\text { conditions }(\mathrm{kg} / \mathrm{s})\end{array}$ \\
\hline Lower explosion limit-LELm & $\mathrm{Kg} / \mathrm{m}^{3}$ & 0.082370138 & \\
\hline Lower explosion limit-LELv & $\%$ & 2.0000 & $\begin{array}{l}\mathrm{W}_{\mathrm{g}} \text { - discharge rate at sonic } \\
\text { conditions }(\mathrm{kg} / \mathrm{s})\end{array}$ \\
\hline Safety coefficient-k & $(0.5-1)$ & 0.5 & 0.103764 \\
\hline Universal gas constant-R & $\mathrm{J} / \mathrm{kmol} . \mathrm{K}$ & 8314.0000 & $\begin{array}{l}\text { Rc-Sonic } \\
\text { characteristic }\left(\mathrm{m}^{3} / \mathrm{s}\right)\end{array}$ \\
\hline Inner Pressure-P & $\mathrm{Pa}$ & 600000.0 & 3.926692 \\
\hline Air Pressure-Pair & $\mathrm{Pa}$ & 101.325 & $\begin{array}{l}\text { Rc-Sonic } \\
\text { characteristic }\left(\mathrm{m}^{3} / \mathrm{s}\right)\end{array}$ \\
\hline Density of enlarged gas- $\rho$ & $\mathrm{Kg} / \mathrm{m}^{3}$ & 2.0977 & 4.946578 \\
\hline Temperature-T & ${ }^{\circ} \mathrm{C}$ & 40.0 & Dilution degree \\
\hline Air Temperature- $\mathbf{T}_{\text {air }}$ & $\mathrm{K}$ & 313.15 & Medium dilution \\
\hline Discharge area coefficient- $C_{d}$ & & 0.75 & $\begin{array}{l}\text { Zone Radius at subsonic } \\
\text { conditions }\end{array}$ \\
\hline Air flow velocity & $\mathrm{m} / \mathrm{s}$ & 0.50 & 10.8 \\
\hline
\end{tabular}

One of the things to be considered in these calculations is that the calculation effect of the parameters is large. Many values such as discharge characteristic, degree of dilution, hazardous area distances are calculated using numerical formulas. However, in some determinations, it is understood that the use of values based on approximation and observation is also necessary. The ventilation rate should be selected using the table, the determination of the source of discharge (secondary, main, and continuous) and its shape (jet, diffusion and heavy gas) should generally be done through qualitative observation. 
The Risk Calculation of Hazardous Zones Created By Flammable And Explosive Chemicals, LPG Tank Exampl...

This makes relative evaluations necessary and thus different results are obtained from the calculations made by different people. Studies are underway that may allow more detailed calculations on explosion zones. Miranda T. J. et al. Compared the UNE 60079/10/1 standard method with computed fluid dynamics (BAD) methods in the calculation of the zones and risks of explosive atmospheres and concluded that the BAD method is more advantageous than the standard 60079/10/1 method [8]. They stated that the advantage of the method was that it allowed the calculation of the volume of the potentially explosive atmosphere. Ferrero et al. Reported the effect of an important factor causing explosion in their studies on the explosion temperature of tetrafluoroethylene gas in the reactor environment [17]. It should be considered that as the firing temperature decreases as the pressure of tetrafluoroethylene increases and this fact should also be taken into account when working with other explosive flammable chemicals. In another study, it was carried out that the structure of the molecules and the functional chemical groups attached to the molecules can change the ignition temperature [18]. In the study, the evaporation, and the changing flaming behaviors of some amine groups according to their functional molecular structures have been investigated using the methods suggested by Rowley and Wilding. The derivation of "FP $1 / 4207: 2+23: 43 \mathrm{nC}-7: 363 \mathrm{nH}+49: 41 \mathrm{nN}+64$ : 79IP-62: 96DP" has been proposed. Taking into account the increased IP and reduced DP factors in this derivation and the $\mathrm{C}, \mathrm{H}, \mathrm{N}$ numbers in the additional groups in the molecule, the correct result was found without deviating $137 \mathrm{~K}$ from the calculated flammability degree.

\subsection{Potential hazard scenarios as a result of LPG tank explosion - potential explosion severity}

Different reason could cause an explosion or firing of a leaking chemical. External factors, earthquakes, material defects and others indirectly may result in leakage and fire after meet sparking source when the air-fuel mixture is flammable combinations. The leak substance has two main threats: it may threat the alive which breathe the toxic vapor and fire or explosion. It was described how the leak from fuel tank may disperse and result in a fire or explosion in Figure 4.

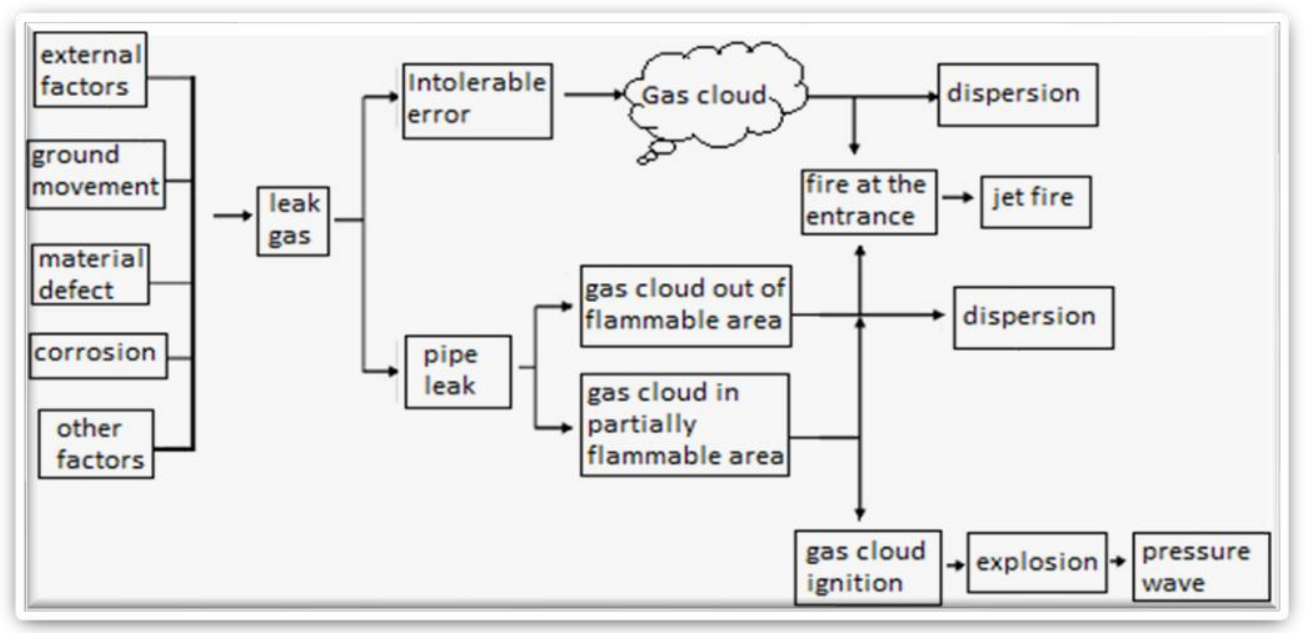

Figure 4. LPG Tank Hazard route

When evaluating the results obtained from the ALOHA program, attention should be paid to concentration irregularities, especially at very low wind speeds, very stable atmospheric conditions, wind direction changes and sloping terrain, and near the source of the leak. In the 
The Risk Calculation of Hazardous Zones Created By Flammable And Explosive Chemicals, LPG Tank Exampl...

ALOHA program, the effects of chemical reactions, particles, chemical mixtures, and land factors are not taken into account. In addition, the ALOHA program is not used in chemical dispersions that are effective at distances greater than $10 \mathrm{~km}$, causing cloud formation, and chemical dispersions lasting over an hour.

In the program, the risk of the tank environment during a fire is determined by the level of thermal radiation emitted, and these danger zones are expressed in three different colours: red, orange, and yellow. The most dangerous area is the red, the least dangerous is the yellow zone. The red danger zone is the area where the thermal radiation is over $10 \mathrm{~kW} / \mathrm{m}^{2}$ and that results in death after 60 seconds of exposure. Thermal radiation in the orange hazard zone is between $5-10 \mathrm{~kW} / \mathrm{m}^{2}$, and 60 seconds exposure poses a risk of secondary burns. In the yellow danger zone where the thermal radiation is between $2-5 \mathrm{~kW} / \mathrm{m}^{2}$, there is a risk of burns within 60 seconds Figures 5-9. Chemical properties were given in Table 6.

Table 6. Information about the tank

\begin{tabular}{|c|c|}
\hline & $\begin{array}{l}\text { Boiling point }:-1.1^{\circ} \mathrm{C} \\
\text { Vapor pressure }:>1 \mathrm{~atm}\end{array}$ \\
\hline $\begin{array}{rr}\text { Location } & \text { :Gebze Kocaeli } \\
\text { Date } & : 15.01 .2019\end{array}$ & : $4 \mathrm{~m} / \mathrm{s}$ (open \\
\hline Lower explosion limit (LEL) : 16000 ppm & Air temperature : $8^{\circ} \mathrm{C}$ \\
\hline Upper explosion limit (UEL) : 84000 ppm & Tank Radius \\
\hline Chemical mass inside tank : $22.286 \mathrm{Kg}$ & Tank length \\
\hline & Tank Volume \\
\hline & Tank fill rate \\
\hline
\end{tabular}

\subsection{Modeling of flammable liquid vapours spreading to atmosphere in case of possible leakage from LPG tank or flanges}

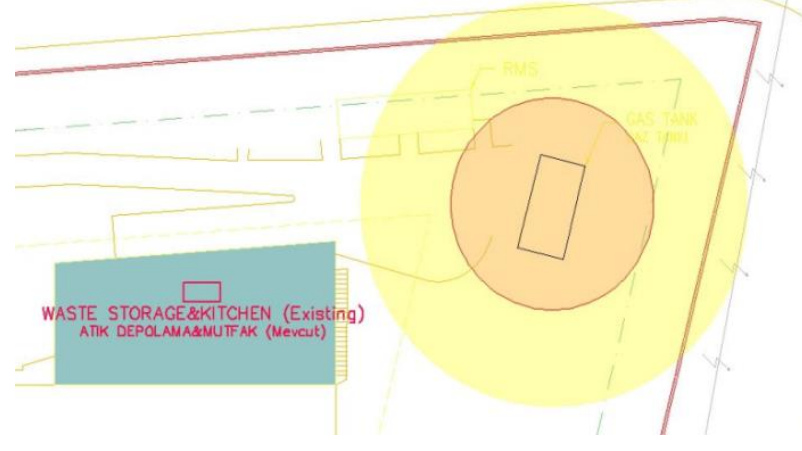

Figure 5. Toxic vapor cloud hazardous area
Toxic vapor cloud hazardous area,

Red: $11 \mathrm{~m}-(53000 \mathrm{ppm}=$ AEGL-3 (60 min.)

Orange: $11 \mathrm{~m}-(17000 \mathrm{ppm}$ = AEGL-2 (60 min.)

Yellow: $21 \mathrm{~m}-(5500 \mathrm{ppm}=$ AEGL-1 (60 min.) 
The Risk Calculation of Hazardous Zones Created By Flammable And Explosive Chemicals, LPG Tank Exampl...

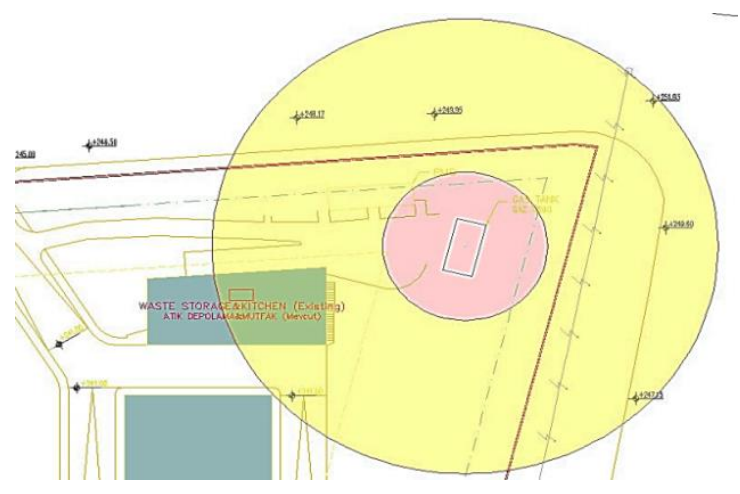

Figure 6. Flammable vapor cloud hazardous area illustration

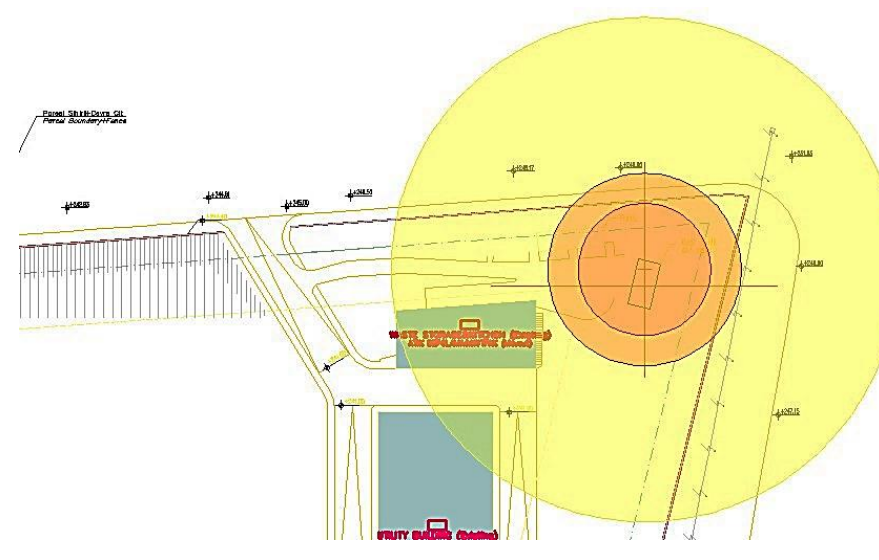

Figure 7. Vapor Cloud Explosion Zone
Flammable vapor cloud hazardous area,

Red: 14 m (9600 ppm = \% 60 $\mathrm{LEL}=$ Flame pocket)

Yellow: $43 \mathrm{~m} \mathrm{(1600} \mathrm{ppm} \mathrm{= \%}$ 10)

The explosion area of the vapor cloud,

Red Zone: greater than 0.5 bar (collapse of structures),

$\mathrm{r}=55$ meters

Orange Zone: greater than 0.2 bar (probability of serious injury), $r=20$ meters

Yellow Zone: greater than 2.5 bar (shattering of glass),

$\mathrm{r}=15$ meters

\subsection{Modeling of combustion of flammable liquid vapor like jet fire in case of possible leakage from LPG tank or flanges}

\subsubsection{Dangerous area of thermal radiation}
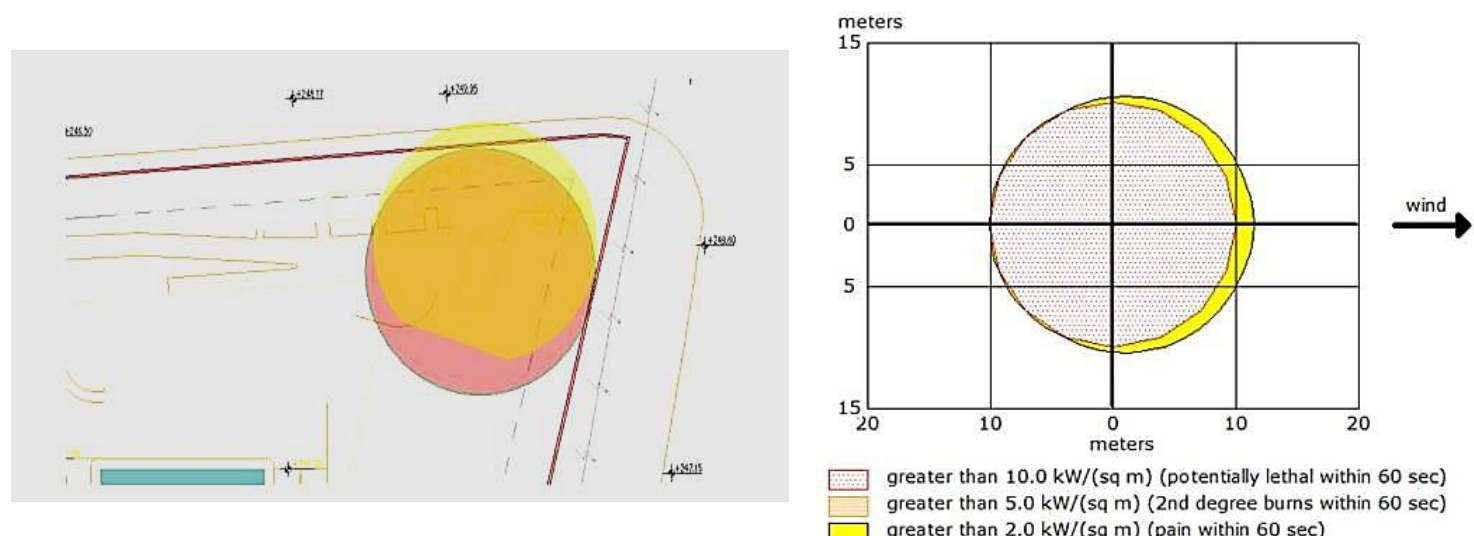

Figure 8. Thermal Radiation Zone

Conclusion/Comment: In Jet fire fires, it has been observed that the workers in an area of 10 $\mathrm{m}$ have a risk of death. 
The Risk Calculation of Hazardous Zones Created By Flammable And Explosive Chemicals, LPG Tank Exampl...

\subsubsection{Dangerous area modeling when the tank explodes like a fireball}

In this study, it is assumed that in the event of a possible leak, the second (Jet fire) and third (BLEVE) scenarios will occur. Calculations for both selected scenarios were made separately, and the results were modelled separately using the experimental design method. BLEVE explosion is a rare occurrence that only occurs when the internal pressure of the tank has increased too much, and the drain openings of the tank cannot relieve the increased pressure. This situation usually occurs when the tank heats itself after a "Jet fire" type fire that starts with a leak from the tank, or a fire in another nearby tank heats that tank by radiating and convection. For this reason, in this study, it is assumed that the combustion reaction will occur (Jet fire) primarily at the leakage point.

\subsubsection{Dangerous area of thermal radiation}

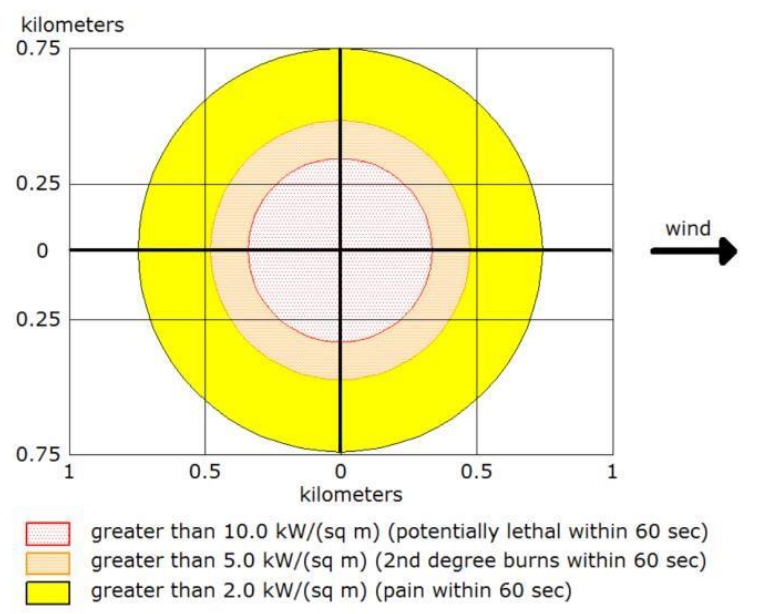

Figure 9. Thermal Radiation Hazardous Area

It has been calculated that a fatal zone may occur in an area of $300 \mathrm{~m}$ as a result of the expected BLEVE explosion in case of leakage of a $50 \mathrm{~m}^{3} \mathrm{LPG}$ tank and no intervention after the jet fire.

\section{Discussion}

The data obtained from the calculations showed the existence of Zone 2 where explosion may occur in case of LPG leakage. Risk value calculated in simple $5 \times 5$ matrix is calculated as 12 Table 7. The risk situation has been tried to be determined by using many approximate values and relative approaches both in risk score calculations and in calculations of the previous region and gas dispersion diameter.

Table 7. Risk assessment and measures to be taken

\begin{tabular}{|c|c|c|c|c|}
\hline Flammable substance & \multicolumn{2}{|l|}{ LPG } & Radius of Dangerous Area & $10.8 \mathrm{~m}$ \\
\hline Equipment & \multicolumn{2}{|c|}{ EX II 3G IIB T2 } & Category of Danger Zone & Zone 2 \\
\hline Source of discharge: & \multicolumn{2}{|c|}{ Leakage from flanges } & People to be Affected: & $\begin{array}{l}\text { All } \\
\text { employees }\end{array}$ \\
\hline Risk Assessment & possibility & severity & Score & \\
\hline Matrix & 3 & 4 & 12 & \\
\hline
\end{tabular}


The Risk Calculation of Hazardous Zones Created By Flammable And Explosive Chemicals, LPG Tank Exampl...

Since some of these approximations are based on the experience of the technical staff performing the calculation, it is possible that the margin of error is high in the approximation of the less experienced people. For this reason, it is necessary to precisely determine and implement the measures to be taken, considering the risk score.

In the calculations made according to the standards, the area of 10.8 meters was calculated as the danger zone during filling and in case of leakage from the flanges. The equipment to be used in this area must be EX II 3G IIB T2 non-sparking (exproof) materials. Storage within this area should be prohibited. The choice of exproof gas alarm detector used in the LPG station is a suitable and industrial type gas detector. It is necessary to try to get an idea about the corrosion dimensions by making a non-destructive examination on the pipes. Corrosion measurements are also an important test in determining the maintenance periods of the entire facility.

The clothes of the personnel who will work in the hazardous area should be $100 \%$ cotton, i.e. ESD. Work Shoes should also have ESD feature $\left(<3.5 \times 10^{7} \mathrm{ohms}\right)$. It must be determined whether the LPG system is in the lightning rod protection area. The usage, maintenance and repair instructions of all electrical devices used in this environment should be created and kept in the relevant area. No work that could cause sparking should be done in the hazardous area and Explosive atmosphere "EX" sign should be hung in this area.

Employees should be taught what to do in emergencies (fire, glare, explosion, etc.). If any work is to be carried out around the dangerous area, the 'work permit system' should be implemented and the employees should be inspected at certain intervals. In this area, no tools other than Exproof hand tools and work equipment should be used. Hand tools with these features should be purchased for the maintenance team.

All electrical equipment to be used in the Explosive Environment must be of ex-proof standards (EX II 3G IIC T6). Grounding measurements should be made in annual periods and the measured values should be below $10^{6} \mathrm{Ohm}$ for static electricity, reports should be prepared annually and kept in the relevant file.

Limit pressure values of manometers must be marked in red line. Lightning Protection System (LPS) must be connected to the grounding system with the equipotential busbar system. When a change is made in a building or its installation, it should be checked whether the existing LPS is still maintained in accordance with this Regulation. If a nonconformity is detected during the inspection, necessary corrections should be made immediately.

Lightning rod system Inspection and maintenance programs should be defined by the LPS designer or installer with the participation of the building owner (s) or their authorized person or his appointed representative. The maintenance program should be described in detail and the maintenance programs should be carried out without delay. If we take into account that the minimum ignition energy of $75 \%$ butane is $0.25 \mathrm{~mJ}$, it should not be filled at speeds higher than $1 \mathrm{~m} / \mathrm{s}$.

A certificate of conformity for ATEX requirements of the tank to be filled should be provided and the wall thickness of the tank should be checked by periodic corrosion controls. There should be at least 2 wheeled fire extinguishers of $30 \mathrm{~kg}$ right next to the LPG Station. Fire extinguishers to be placed next to the tanks should be in a place that is hung from the wire mesh and easily accessible, except for the wire mesh (TS 862-1 EN 3-1). 
The Risk Calculation of Hazardous Zones Created By Flammable And Explosive Chemicals, LPG Tank Exampl...

Liquid flow directions should be marked with arrows on pipes that are exposed above ground. There must be a distance of at least $7.5 \mathrm{~m}$ between the vehicle fuelling the tank and any above ground tank.

To prevent overfilling, there should be alerts that will give an audible alarm when the liquid level in the tank reaches $90 \%$ of the tank capacity and automatically stop the liquid transfer when the liquid level reaches $80 \%$ of the tank capacity. These beepers should never affect normal or emergency ventilation.

It is required to be in the mechanism that known as the "dead man button" to the tanks, allowing the gas flow by keeping it pressed continuously and stopping the filling if not pressed should be used to prevent the transfer when operator leaves from the filling area during the transfer.

Warning signs such as "LPG", "No Smoking", "Approach with Fire", "Flammable and Flammable Substance", "No Other Authorized Person", "Turn Off Cell Phone" should be placed in easily visible places in the LPG storage area and LPG storage tank filling area.

In accordance with the Regulation on the Protection of Employees from the Dangers of Explosive Atmospheres, employees must be given explosion protection training. Necessary measures should be taken regarding grounding. It was observed that there was an equipotential grounding system in the study area, but not enough point measurements were made. Grounding should be reported according to the results of the measurements made from each point and it should be clearly stated which type of electrical grounding. Safety instructions and the issues that employees must comply with should be reported. Zone 1: Considering the zone calculations according to the CE certified ATEX, suitable electrical devices should be used for the LPG filling tanker or tank in an area of 2.5 meters. It should be kept in mind that occupational accidents include all unwanted situations such as death, severe injury, injury that have the potential to harm people and workplace devices and machines.

\section{Conclusion}

It is an important step in preventing hazards to know the extent of hazardous environments that are frequently used in industrial areas and will form explosive atmospheres by leaking into the environment and mixing with air in certain proportions. In this study, LPG leakage calculations that can create explosive atmosphere within the scope of TSE EN 60079-1 standard have been made. The hazardous areas around the LPG tank, the distances of these areas and the zone classification have been determined. Taking these calculations into account, the measures to be taken and the protective equipment to be used can be as follows:

Chemical leakage can damage the environment and living with the toxic, flammable, explosion and, thermal radiation effect mainly. In case of any kind of damages, the effective areas of chemicals were found to cover a large area changing from 10 to $300 \mathrm{~m}$.

Calculations of explosive atmospheres in industrial facilities will give more accurate results in hazard identification. An effective risk assessment and explosion protection can be done by precisely determining the distances of explosive atmospheres in the workplace.

Burning/explosions caused by the contact of dangerous chemicals with oxygen and spark can cause fatal, serious injury or serious damage accidents. Care should be taken to select the electrical and sparking equipment to be used in the production process or in the warehouse in 
the ex-proof category. Since such calculations are dependent on many variables such as the type, volume, connections of the chemical in the workplace, the ventilation conditions of the environment and the condition of the leakage, it has been understood that the result can be reached for each enterprise with calculations specific to that environment.

Thanks to these calculations, it was concluded that less costly ex-proof equipment can be used instead of high-cost ex-proof electrical equipment that must be used at any time. In order to prevent possible liquid-gas ATEX explosions in order to prevent the spread of fire, explosionproof sections in the form of block concrete and separate buildings should be created in the warehouses.

\section{Acknowledgement}

The authors have no conflicts of interest to declare that relevant to the content of this article and all authors confirm that study for publication. All authors contributed to study conception and design.

\section{Conflict of Interest}

The authors have no conflicts of interest to declare that relevant to the content of this article and all authors confirm that study for publication. All authors contributed to study conception and design.

\section{Author Contributions}

All authors contributed to the study conception and design. Material preparation and data collection was performed by Omer Ahmet Uslu, analysis and interpretations were performed by Dr. Huseyin Gumus and Dr. Bulent Buyukkidan. The first draft of the manuscript was written by Dr. Huseyin Gumus and all authors commented on previous versions of the manuscript. All authors read and approved the final manuscript.

\section{References}

[1] L. Kotek, P. Trávníček, P. Blecha, Accident analysis of european biogas stations, Chemical Engineering Transactions. 43 (2015) 1933-1938. doi:10.3303/CET1543323.

[2] A.M. Nassimi, M. Jafari, H. Farrokhpour, M.H. Keshavarz, Constants of explosive limits, Chemical Engineering Science. $173 \quad$ (2017) 384-389. doi:10.1016/j.ces.2017.08.011.

[3] F. Van den Schoor, F. Norman, K. Vandermeiren, F. Verplaetsen, J. Berghmans, E. Van den Bulck, Flammability limits, limiting oxygen concentration and minimum inert gas/combustible ratio of $\mathrm{H} 2 / \mathrm{CO} / \mathrm{N} 2 /$ air mixtures, International Journal of Hydrogen Energy. 34 (2009) 2069-2075. doi:10.1016/j.ijhydene.2008.12.038.

[4] G. Shu, B. Long, H. Tian, H. Wei, X. Liang, Evaluating upper flammability limit of low hydrocarbon diluted with an inert gas using threshold temperature, Chemical Engineering Science. 138 (2015) 810-813. doi:10.1016/j.ces.2015.09.013.

[5] H. Miao, L. Lu, Z. Huang, Flammability limits of hydrogen-enriched natural gas, International Journal of Hydrogen Energy. $36 \quad$ (2011) 6937-6947. doi:10.1016/j.ijhydene.2011.02.126.

[6] Ö. A. Uslu "Endüstriyel Tesislerdeki Yanıcı, Parlayıcı Kimyasal Sıvıların Atmosfer Patlamalarının (Atex) Teorik Ve Uygulamalı Olarak Hesap Edilerek Önlemlerinin 
The Risk Calculation of Hazardous Zones Created By Flammable And Explosive Chemicals, LPG Tank Exampl...

Belirlenmesi" Yüksek Lisans Tezi, Kimya Bölümü, Kütahya Dumlupınar Üniversitesi, Kütahya, Türkiye, (2019).

[7] N.D.D. Carareto, C.Y.C.S. Kimura, E.C. Oliveira, M.C. Costa, A.J.A. Meirelles, Flash points of mixtures containing ethyl esters or ethylic biodiesel and ethanol, 96 (2012) 319-326. doi:10.1016/j.fuel.2012.01.025.

[8] J. Telmo Miranda, E. Muñoz Camacho, J.A. Fraguela Formoso, J. de D. Rodríguez García, Comparative study of the methodologies based on Standard UNE 60079/10/1 and computational fluid dynamics (CFD) to determine zonal reach of gas-generated Atex explosive atmospheres, Journal of Loss Prevention in the Process Industries. 26 (2013) 839-850. doi:10.1016/j.jlp.2013.02.015.

[9] T. G. Rodrigues, "A Software Application to Define and Rank Atex Zones" M.S thesis, Faculdade de Engenharia da (Faculty of Engineering),Universidade do orto (TheUniversity of Porto), Portugal, 2016.

[10] F. Mahnamfar, Y. Abdollahzadeh, N. Ağıralioğlu, Flood Risk Analysis of Residential Areas at Downstream of the Elmali Dam, Academic Platform Journal of Natural Hazards and Disaster Management. 1 (2020) 49-58.

[11] M.M. Van der Voort, R.M.M. van Wees, J.M. Ham, M.P.N. Spruijt, A.C. van den Berg, P.C.J. de Bruijn, P.G.A. van Ierschot, An experimental study on the temperature dependence of $\mathrm{CO}_{2}$ explosive evaporation, Journal of Loss Prevention in the Process Industries. 26 (2013) 830-838. doi:10.1016/j.jlp.2013.02.016.

[12] E.E. Layık, "Gıda Sektöründe Toz Patlamalarinin Araştirilmasi Ve Patlamadan Korunma Dokümaninin Hazirlanmasi Bir Uygulama Örneği" İs Sağlığı ve Güvenliği Uzmanlık Tezi, T.C. Çalışma ve Sosyal Güvenlik Bakanlığı İş Sağlığı ve Güvenliği Genel Müdürlüğü, Ankara, Türkiye, 2016.

[13] U. Mevlevıglu, M.A.N. Kadırgan, G. Alev Çiftçioğlu, Kimya Endüstrilerinde Patlama ve Yangınların Önlenmesi ve İlgili Vaka Çalışmaları, International Journal of Advances in Engineering and Pure Sciences. (2019) 36-46. doi:10.7240/jeps.457561.

[14] P. Trávníček, L. Kotek, P. Junga, T. Vítěz, K. Drápela, J. Chovanec, Quantitative analyses of biogas plant accidents in Europe, Renewable Energy. 122 (2018) 89-97. doi:10.1016/j.renene.2018.01.077.

[15] P.L. Barros, A.M. Luiz, C.A. Nascimento, A.T.P. Neto, J.J.N. Alves, On the nonmonotonic wind influence on flammable gas cloud from CFD simulations for hazardous area classification, Journal of Loss Prevention in the Process Industries. 68 (2020). doi:10.1016/j.jlp.2020.104278.

[16] Patlayıcı ortamlar - Bölüm 10-1: Alanların sınıflandırılması-Patlayıcı gaz ortamları Standard1, Türk Standartları Enstitüsü, TS EN 60079-10-1, 2015

[17] F. Ferrero, R. Meyer, M. Kluge, V. Schröder, T. Spoormaker, Study of the spontaneous ignition of stoichiometric tetrafluoroethylene-air mixtures at elevated pressures, Journal of Loss Prevention in the Process Industries. 26 (2013) 759-765. doi:10.1016/j.jlp.2013.02.008.

[18] M.H. Keshavarz, S. Moradi, A.R. Madram, H.R. Pouretedal, K. Esmailpour, A. Shokrolahi, Reliable method for prediction of the flash point of various classes of amines on the basis of some molecular moieties for safety measures in industrial processes, Journal of Loss Prevention in the Process Industries. 26 (2013) 650-659. doi:10.1016/j.jlp.2013.01.005. 